\title{
Estrogen Receptor Positive/Progesterone Receptor Negative Breast Carcinomas: A Subgroup Deserves Particular Interest
}

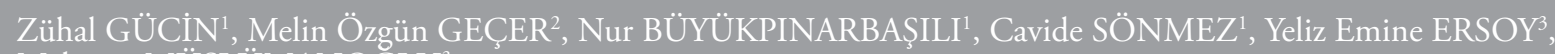
Mahmut MÜSLÜMANOGLU ${ }^{3}$

${ }^{1}$ Department of Pathology, Bezmialem Vakif University Faculty of Medicine, Istanbul, Turkey

${ }^{2}$ Clinic of Pathology, Kartal Lütfü Kırdar Research and Training Hospital, Istanbul, Turkey

${ }^{3}$ Department of General Surgery, Bezmialem Vakif University Faculty of Medicine, Istanbul, Turkey

\section{ABSTRACT}

Objective: Breast carcinomas positive for the estrogen receptor $(\mathrm{ER}+)$ but negative for the progesterone receptor (PR-) have unfavorable prognostic features and are resistant to tamoxifen therapy. The goal of this study was to highlight the significance of PR- breast carcinomas. Methods: Therefore, 146 breast carcinomas comprising $87 \mathrm{ER}+/ \mathrm{PR}+$ and $59 \mathrm{ER}+/ \mathrm{PR}-$ carcinomas were examined. These two groups were compared in terms of age; tumor type; tumor size; histologic grade; presence of an in situ component; lymphovascular and perineural invasion; and ER, PR, c-Erb B2, Ki-67, and epidermal growth factor receptor (EGFR) status.

Results: While the number of metastatic lymph node and related pN2+pN3 tumors were found to be significantly higher in the ER+/ PR- group, the differences with respect to the tumor size, metastatic lymph node size, and frequency of lymphovascular invasion were nearly significant.

Conclusion: ER+/PR- tumors have an unfavorable prognosis and show a clinical behavior closer to triple negative ones, although classified as luminal tumors. Revealing the mechanisms causing these differences will enhance the success of breast cancer therapy.

Keywords: Breast carcinoma, estrogen receptor, progesterone receptor, luminal type, prognosis

\section{Introduction}

Among breast carcinomas, invasive ductal carcinoma forms the largest group of histological types and luminal carcinoma forms the largest group of molecular types. As tumors form such a large group, they are not expected to display one type of biological behavior, and thus, it is quite normal that their responses to treatment differ. There must be some mechanisms that cause these differences. The discovery of these mechanisms will enable the development of new treatment options. In the luminal group, breast carcinomas that are estrogen receptor positive/progesterone receptor negative (ER $\left./ \mathrm{PR}^{-}\right)$are resistant to tamoxifen, have a higher proliferative activity, and display more frequent and earlier recurrence. The purpose here is to demonstrate the poor prognostic features of $\mathrm{ER}^{+} / \mathrm{PR}^{-}$breast carcinomas, to draw attention to their importance as a separate subtype, and to provide a preliminary study that will form the basis for further studies.

\section{Methods}

In this study, a total of 146 breast carcinoma cases that were diagnosed in two different centers (104 and 42 cases, respectively) are discussed. After the patients' surgical samples were fixed for $24 \mathrm{~h}$ in $10 \%$ buffered formaldehyde, standard follow-up was performed. Eighty-seven cases were $\mathrm{ER}^{+} / \mathrm{PR}^{+}$and 59 of them were $\mathrm{ER}^{+} / \mathrm{PR}^{-}$. Using the patients' pathology reports, features, such as the age of the patient, type and size of the tumor, histological grade, lymph node (LN) status, multifocality, presence of in situ components, lymphovascular invasion (LVI), and perineural invasion (PNI) were compared. ER (rabbit, SP1, Thermo Scientific), PR (rabbit, SP2, Thermo Scientific), and Ki-67 (rabbit, SP6 Biocare) scores and HER1 (EGFR) (rabbit, EP38Y, Thermo Scientific) and HER2 (c-erb B2) (Mouse e2-4001+3B5, Thermo Scientific) were immunohistochemically evaluated. Immunohistochemical analysis was automatically performed on a Ventana Benchmark XT (USA) device.

If the ER and PR scores were over 1\%, this was considered as positive. For the HER2 (c-erb B2) status, if the immunohistochemical score was 3 and the score that was supported by in situ hybridization was 2 , the results were considered positive.

Address for Correspondence: Zühal Gücin; Department of Pathology, Bezmialem Vakif University Faculty of Medicine, Istanbul, Turkey . Phone: +90 2124531772 Mobile: 05325957633 E-mail: zgucin@yahoo.com 
Because there were no definite criteria on EGFR (HER1)positive status, all cytoplasmic stainings were assessed. The HER1 and HER2 statuses were discussed both separately and in terms of their association. When the Ki-67 score was $15 \%$ or above, it was considered to be high.

\section{Statistical analysis}

Descriptive statistics were given as mean \pm standard deviation. Quantitative variables, such as age, tumor size/diameter, LN size/diameter, number of LNs, and number of metastases, were tested for normal distribution suitability via the Kolmogorov-Smirnov test. It was found that all the variables, except age, did not comply with a normal distribution. Age, which complied with a normal distribution, was compared using the t-test and other variables were compared using the Mann-Whitney $U$ test. With their percentages given, two state properties, such as type of tumor, multifocality, LVI, PNI, presence of an in situ component, Ki-67, and EGFR, were assessed using a chi-square test and Fisher's exact test.

\section{Results}

Eighty-seven (59.6\%) patients who were included in the study were $\mathrm{ER}^{+} / \mathrm{PR}^{+}$and 59 (40.4\%) of them were $\mathrm{ER}^{+} / \mathrm{PR}^{-}$. For the cases forming these two groups, when age status was assessed using the t-test and tumor size, number of metastatic LNs, and diameter of LN metastases were evaluated using the Mann-Whitney U test, the number of metastatic LNs was significantly higher in the $\mathrm{PR}^{-}$group $(\mathrm{p}=0.018)$. The difference was determined to be nearly significant in terms of LN metastasis size and tumor size ( $\mathrm{p}=0.066$ and $\mathrm{p}=0.051)$ (Table 1). Other results of comparisons are summarized in Table 2. According to this, whereas there is a nearly significant difference in terms of the presence of LVI, the status of advanced $\mathrm{LN}$ metastasis ( $\mathrm{pN} 2$ and $\mathrm{pN} 3$ ) was observed to be significantly more frequent in the $\mathrm{PR}^{-}$group $(\mathrm{p}=0.002)$.

\section{Discussion}

Estrogen and ER play key roles in normal breast development and the formation of breast cancer (1). Progesterone is regulated by estrogen, and its synthesis requires estrogen and ER (1). ER and PR statuses are often correlated with each other. However, $\mathrm{ER}^{+} / \mathrm{PR}^{-}$tumors form up to $15 \%-25 \%$ of breast cancer cases $(2,3)$. Although these tumors are $\mathrm{ER}^{+}$, they are tamoxifen resistant, have higher proliferative activity, exhibit more genomic variability, and are a different group in terms of clinical and biological behavior $(1,2,4-6)$. Following endocrine therapy, whereas for $\mathrm{ER}^{+} / \mathrm{PR}^{+}$tumors, the recurrence rate was $7.6 \%$, for $\mathrm{ER}^{+} / \mathrm{PR}^{-}$tumors, the ratio was found to be $14.8 \%$ (1). In another study, whereas the development of relapses in $\mathrm{PR}^{+}$tumors occurred in approximately 112 months, for $\mathrm{PR}^{-}$tumors, this period decreased to 24 months $(\mathrm{p}=0.005)$ (7). In these tumors, their aggressive behavior is associated with their both being $\mathrm{ER}^{+}$tumors and having a high growth factor signaling. Indeed, in this tumor subgroup, HER1 and HER2 are highly expressed (4).
Table 1. Comparison of $\mathrm{PR}^{+}$and $\mathrm{PR}^{-}$groups in terms of age, tumor size, number of metastases, and size of metastatic LNs. Whereas in PR- tumors, the number of metastatic LNs was significantly higher $(p<0.05)$, tumor size and diameter of metastatic LNs were found to be nearly significantly different $(0.05<p<0.1)$

\begin{tabular}{l|c|c|c|c|c|c|}
\hline & \multicolumn{3}{c}{ Cases } & \multicolumn{3}{c}{ Test } \\
Feature & Group & $\mathbf{( n )}$ & Mean & SD & type & p \\
\hline Age & $\mathrm{PR}^{-}$ & 43 & 53.86 & 10.84 & $\mathrm{t}=0.83$ & 0.405 \\
& $\mathrm{PR}^{+}$ & 34 & 56.12 & 12.79 & & \\
\hline $\begin{array}{l}\text { Tumor } \\
\text { diameter/cm }\end{array}$ & $\mathrm{PR}^{-}$ & 48 & 2.97 & 1.81 & $\mathrm{z}=1.95$ & $0.051^{*}$ \\
\hline PR & 84 & 2.51 & 1.44 & & \\
Number of & $\mathrm{PR}^{-}$ & 24 & 6.04 & 7.41 & $\mathrm{z}=2.38$ & $0.018^{*}$ \\
metastases & $\mathrm{PR}^{+}$ & 71 & 3.42 & 6.92 & & \\
\hline $\begin{array}{l}\text { Diameter of } \\
\text { metastatic }\end{array}$ & $\mathrm{PR}^{-}$ & 32 & 1.91 & 0.96 & $\mathrm{z}=1.83$ & $0.066^{* *}$ \\
LN/cm & $\mathrm{PR}^{+}$ & 29 & 1.43 & 0.95 & & \\
\hline
\end{tabular}

t: t-test, z: Mann-Whitney U test, *significant **nearly significant

SD: standard deviation; PR: progesterone receptor; LN: lymph node

Table 2. Results obtained by comparison of other features. The number of metastatic LNs (number of pN2+pN3 cases) in the $\mathrm{ER}^{+} / \mathrm{PR}^{-}$group is significantly higher $(p<0.05)^{*}$. In the same group, the frequency of LVI was nearly significantly higher $(0.05<p<0.1)^{* *}$

\begin{tabular}{|l|c|c|c|c|}
\hline Feature & $\begin{array}{c}\text { ER } \\
\text { group }\end{array}$ & $\begin{array}{c}\text { ER } \text { (PR }^{+} \\
\text {group }\end{array}$ & Value & P \\
\hline Specific tumor types & $11.9 \%$ & $8 \%$ & 0.591 & 0.442 \\
\hline Multifocality & $23.6 \%$ & $25 \%$ & 0.293 & 0.869 \\
\hline In situ component (+) & $22.2 \%$ & $27.1 \%$ & 0.326 & 0.568 \\
\hline High histological grade & $36.4 \%$ & $24.4 \%$ & 2.321 & 0.128 \\
\hline LVI & $52 \%$ & $28.5 \%$ & 3.335 & $0.068 * *$ \\
\hline PNI & $32.7 \%$ & $30.8 \%$ & 0.049 & 0.824 \\
\hline LN metastasis frequency & $70.3 \%$ & $58.6 \%$ & 1.149 & 0.284 \\
\hline pN2 and pN3 cases & $54.2 \%$ & $21.1 \%$ & 8.536 & $0.002 *$ \\
\hline High Ki-67 score & $65 \%$ & $52 \%$ & 0.734 & 0.392 \\
\hline HER2 overexpression & $28.5 \%$ & $17.2 \%$ & 2.576 & 0.109 \\
\hline HER1/EGFR (+) & $34.1 \%$ & $16.7 \%$ & 2.701 & 0.100 \\
\hline HER1 and HER2 (+) & $15 \%$ & $3.3 \%$ & 2.531 & 0.125 \\
\hline *significant (p<0.05) & **nearly significant (0.05<p<0.1) & \\
\hline $\begin{array}{l}\text { LVI: lymphovascular invasion; PNI: perineural invasion; LN: lymph node; pN: } \\
\text { pathological lymph node stage; ER: estrogen receptor; PR: progesterone }\end{array}$ \\
\hline receptor
\end{tabular}

Bae et al. (6), in their study involving 6980 breast carcinoma patients, determined that cases that are single-hormone positive and patients who are HER2 negative demonstrate prognostic features that are worse and similar to those of triple-negative tumors compared with the $\mathrm{ER}^{+} / \mathrm{PR}^{+} / \mathrm{HER} 2^{-}$ 
group. In this study, the rate of $\mathrm{ER}^{+} / \mathrm{PR}^{-}$cases was found to be $6.9 \%(6)$.

$\mathrm{ER}^{+} / \mathrm{PR}^{-}$tumors are observed in older patients and are larger tumors. They have a higher S-phase fraction. Aneuploidy occurs morre frequently in this group. Elevated HER1 (EGFR) levels are more frequent compared with $\mathrm{ER}^{+} / \mathrm{PR}^{+}$tumors $(25 \%$ vs. $8 \%)$. In our series, although there was not much difference, the rate of EGFR expression was high in the PRgroup $(34.1 \%$ vs. $16.7 \%)$. In the same study, whereas in the $\mathrm{ER}^{+} / \mathrm{PR}^{-}$group, the rate of HER2 overexpression/amplification was $21 \%$, in the $\mathrm{ER}^{+} / \mathrm{PR}^{+}$group, it was $14 \%$ (8). In our study, the rate of overexpression of HER 2 was $17.20 \%$ in the $\mathrm{PR}^{+}$group, whereas in the $\mathrm{PR}^{-}$group, this ratio was $28.60 \%$. Furthermore, HER1 and HER2 levels are reported to be higher in recurrent tumors.

In these tumors, ER levels are low despite their $\mathrm{ER}^{+} / \mathrm{PR}^{-}$status (8). The underlying mechanism of this in these tumors is explained by the occurrence of elevated HER1 and HER2 levels with high levels of growth factor receptors and the presence of "cross-talk" in the signaling pathways initiated by ER. This interference in signaling also explains the tamoxifen resistance (8). In its classically known form, ER status is the basic determining element in endocrine therapy for breast cancer, and most of the $\mathrm{ER}^{-}$cases are already $\mathrm{PR}^{-}$. Only up to $3 \%-5 \%$ of tumors are $\mathrm{ER}^{-} / \mathrm{PR}^{+}$, and in these cases, $\mathrm{PR}$ is used as a marker that shows whether the patient can respond to endocrine therapy. Recently, contrary to earlier claims, it has been emphasized that progesterone is also a proliferative hormone and is involved in the early stages of breast carcinogenesis (9). The $\mathrm{ER}^{+} / \mathrm{PR}^{-}$group is a different subgroup, and although it is $\mathrm{ER}^{+}$, this group is particularly known to be non-responsive to tamoxifen. In these groups, low PR levels, increased growth factor signaling, and increased tumor aggressiveness are discussed $(3,10)$. The loss of PRs after being affected by treatment indicates a poor prognosis (7). HER1 (EGFR) expression is also associated with a poor prognosis. Although HER1 overexpression is associated with high tumor grade and ER- status, some studies have been performed that yielded different results associated with HER3 and HER4, which are the other members of this family, and with different combinations (11-13). Furthermore, in our study, although in $\mathrm{ER}^{+} /$ $\mathrm{PR}^{-}$tumors, co-expression of HER1 and HER2 was high, no statistical significance was detected. TIP30 protein acts as an angiogenesis inhibitor $(14,15)$ and stimulates the production of $\mathrm{p} 53$. Further, $\mathrm{p} 53$ protein, which acts as a tumor suppressor, ensures genome stability and inhibits cancer growth. TIP30 may also regulate $\mathrm{p} 53$ protein by directly binding to it (16). Although TIP30 normally regulates EGF-EGFR endocytic trafficking, in the case of TIP30 deletion, a decrease in EGFR degradation and a prolonged EGFR signal are observed (17). TIP30 deletion increases the population of breast stem cells and progenitor cells and induces susceptibility in the development of $\mathrm{ER}^{+}$luminal tumors $(2,15,18)$. Some studies performed in recent years have emphasized the rela- tionship between TIP30 and tumors of other organs. Whereas TIP30 expression is a good prognostic marker in pancreatic ductal adenocarcinoma, loss of TIP30 has been associated with LN metastasis and downregulation of E-cadherin (19). In lung adenocarcinomas, a relationship between a decrease in TIP30 expression with an increase in EGFR activity and increased nuclear localization and metastasis is indicated (14, 19). Because of these characteristics, TIP 30 protein can be a molecular candidate for a targeted therapy.

\section{Conclusion}

In this study, $\mathrm{PR}^{-}$breast carcinomas were determined to be larger in size, usually higher grade, with more frequent LN metastases, larger in diameter, and exhibiting a greater number of LN involvements. LVI was more common and the Ki-67 score was much higher. Both separately and together, overexpression of HER 1 and HER 2 occurs more frequently. In this study, the number of LN metastases, which was one of the parameters mentioned above, and accordingly the incidence of $\mathrm{pN} 2$ and $\mathrm{pN} 3$ tumors were significantly higher in the $\mathrm{PR}^{-}$group. The size of LN metastases, tumor diameter, and frequency of LVI were found to be nearly significantly different.

With these features, $\mathrm{ER}^{+} / \mathrm{PR}^{-}$tumors seem to deserve more special attention and require to be investigated from various aspects. In this group of breast cancers, there may be more than one mechanism that determines aggressive behavior. Besides growth factor receptors (HER1-4) and, among these, apart from TIP30 deletion, which is associated with HER1 (EGFR), these mechanisms might be associated with protein expression that provides a relationship with tumor stroma. Revealing these and similar mechanisms will help us to understand why these tumors do not respond well to endocrine therapy and to develop new targeted treatment strategies.

Ethics Committee Approval: Due to the retrospective nature of this study, ethics committee approval was waived.

Informed Consent: Due to the retrospective nature of this study, informed consent was waived.

Peer-review: Externally peer-reviewed.

Author Contributions: Concept - Z.G., M.Ö.G., N.B., C.S., Y.E.E., M.M.; Design - Z.G., M.Ö.G., N.B., C.S., Y.E.E., M.M.; Supervision - Z.G., M.Ö.G., N.B., C.S., Y.E.E., M.M.; Funding - Z.G., M.Ö.G.; Materials Z.G., M.Ö.G., Y.E.E.; Data Collection and/or Processing - Z.G., N.B., C.S., M.Ö.G.; Analysis and/or Interpretation - Z.G., N.B.; Literature Review - Z.G., C.S.; Writer - Z.G., N.B.; Critical Review - Z.G., M.Ö.G., N.B., Y.E.E., M.M.

Conflict of Interest: The authors declared no conflict of interest.

Financial Disclosure: The authors declared that this study has received no financial support.

\section{References}

1. Cui X, Schiff R, Arpino G, Osborne CK, Lee AV. Biology of progeseron receptor loss in breast cancer and its implication for endocrine therapy. J Clin Oncol 2005; 23: 7721-35. [CrossRef] 
2. Zhang C, Mori M, Gao S, Li A, Hoshino I, Aupperlee MD, et al. Tip30 deletion in MMTV-Neu mice leads to enhanced egfr signaling and development of estrogen receptor-positive and progesterone receptor-negative mammary tumors. Cancer Res 2010; 70: 10224-33. [CrossRef]

3. Fukua SA, Cui Y, Lee AV, Osborne CK, Hortwitz KB. Insights into the role of progesteron receptors in breast cancer. J Clin Oncol 2005; 23: 931-2. [CrossRef]

4. Thakkar JP, Mehta DG. A review of an unfavorable subset of breast cancer: estrogen receptor positive progesterone receptor negative. Oncologist 2011; 16: 276-85. [CrossRef]

5. Pathiraja TN, Shetty PB, Jelinek J, He R, Hartmaier R, Margossian AL, et al. Progesterone receptor isoform-specific promoter methylation: association of prapromoter methylation with worse outcome in breast cancer patients. Clin Cancer Res 2011; 17: 4177-86. [CrossRef]

6. Bae SY, Kim S, Lee JH, Lee HC, Lee SK, Kil WH, et al. Poor prognosis of single hormone receptor positive breast cancer: similar outcome as triple-negative breast cancer. BMC Cancer 2015; 15: 138. [CrossRef]

7. Bogina G, Bortesi L, Marconi M, Venturini M, Lunardi G, Coati F, et al. Comparision of hormonal receptor and HER-2 status between breast primary tumours and relapsing tumours: clinical implications of progesteron receptor loss. Virchows Arch 2011; 459: 1-10. [CrossRef]

8. Arpino G, Weiss H, Lee AV, Schiff R, De Placido S, Osborne CK, Elledge RM. Estrogen receptor-positive, progesterone receptor-negative breast cancer: association with growth factor receptor expression and tamoxifen resistance. J Natl Cancer Inst 2005; 97: 1254-61. [CrossRef]

9. Lydon JP, Edwards DP. Finally! A model for progesteron receptor action in normal human breast. Endocrinology 2009; 150: 2988-90. [CrossRef]

10. Jacobsen BM, Schittone SA, Richer JK, Hortwitz B. Progesteron-independent effects of human progesteron receptors (PRs) in estrogen receptor-positive breast cancer: PR isoform-specific gene regulation and tumor biology. Mol Endocrinol 2004; 19: 574-87. [CrossRef]
11. Badovinac-Crnjevic T, Jakic-Razumovic J, Podolski P, Plestina S, Sarcevic $B$, Munjas R, Vrbanec D. Significance of epidermal growth factor receptor expression in breast cancer. Med Oncol 2011; 28(Suppl 1): S121-8. [CrossRef]

12. Abd El-Rehim DM, Pinder SE, Paish CE, Bell JA, Rampaul RS, Blamey RW, et al. Expression and co-expression of the members of the epidermal growth factor receptor family in invasive breast carcinoma. Br J Cancer 2004; 91: 1532-42. [CrossRef]

13. Witton CJ, Reeves JR, Going JJ, Cooke TG, Bartlett JM. Expression of the HER1-4 family of receptor tyrosine kinases in breast cancer. J Pathol 2003; 200: 290-7. [CrossRef]

14. Li A, Zhang C, Gao S, Chen F, Yang C, Luo R, Xiao H. TIP30 loss enhances cytoplasmic and nuclear EGFR signaling and promotes lung adenocarcinogenesis in mice. Oncogene 2013; 32: 2273-81. [CrossRef]

15. Pecha J, Ankrapp D, Jiang C, Tang W, Hoshino I, Bruck K, et al. Deletion of Tip30 leads to rapid immortalization of murine mammary epithelial cells and ductal hyperplasia in the mammary gland. Oncogene 2007; 26: 7423-31. [CrossRef]

16. Lee SH, Ju SK, Lee TY, Huh SH, Han KH. TIP30 directly binds p53 tumor suppressor protein in vitro. Mol Cells 2012; 34: 495-500. [CrossRef]

17. Zhang C, Li A, Zhang X, Xiao H. A novel TIP30 protein complex regulates EGF receptor signaling and endocytic degradation. J Biol Chem 2011; 286: 9373-81. [CrossRef]

18. Chen F, Li A, Gao S, Hollern D, Williams M, Liu F, et al. Tip30 controls differentiation of murine mammary luminal progenitor to estrogen receptor-positive luminal cell through regulating FoxA1 expression. Cell Death Dis 2014; 5: e1242. [CrossRef]

19. Guo S, Jing W, Hu X, Zhou X, Liu L, Zhu M, et al. Decreased TIP30 expression predicts poor prognosis in pancreatic cancer patients. Int J Cancer 2014; 134: 1369-78. [CrossRef] 